\title{
COMMUNITY-BASED LEARNING FOR INTERNATIONAL GRADUATE STUDENTS Impact and Implications
}

\author{
Linyuan Guo-Brennan, Charlene VanLeeuwen, Mary M. MacPhee, and \\ Michael Guo-Brennan
}

\section{Abstract}

Integrating community-based learning (CBL) into graduate education has gained attention in bigher education during the past decade because CBL allows students to inculcate professional values and ethics, situate academic knowledge and understanding in contexts, and practice academic citizenship through serving communities with disciplinary knowledge and skills. In a North American bigher education context, about balf of the graduate student population are international students, who have needs in several areas. However, their experiences in CBL are under-investigated and scarcely documented in existing literature and scholarship in either community-based learning or international education. Drawing on international students' experiences in a graduate program infused with CBL components in Canadian higher education, this mixed methods case study examined the impact of CBL on international students' developments in five areas: academic, sociocultural, personal, professional, and global citizenship. Through discussions on the benefit, barriers, and implications of providing CBL to international graduate students, this article offers recommendations for improved higher education policy, programs, and praxis to make CBL more inclusive and responsive to international graduate students.

As an educational philosophy, approach, and pedagogy, community-based learning (CBL) provides students with experiential learning opportunities in community settings and outside of classrooms (Bringle \& Clayton, 2012). CBL allows students to gain a deeper understanding of course content, a broader appreciation of the discipline, and an enhanced sense of personal values and civic responsibility through community engagement and services (Hatcher \& Bringle, 2012; Jacoby, 2015; Steinberg, Hatcher, \& Bringle, 2011). Existing literature has extensively documented the benefits CBL offers to students, such as a deeper understanding of course content, broader appreciation of discipline, enhanced sense of personal values, civic learning, personal growth, career/professional development, and increasing understanding of community and social responsibility (Bowman, 2011; Celio et 
al., 2011; Duncan \& Taylor, 2012; Jameson et al., 2013; Lockeman \& Pelco, 2013; Mitchell et al., 2012; Novak et al., 2007; Reed et al., 2015; Warren, 2012; Yorio \& Ye, 2012). However, the majority of CBL scholarship has focused on undergraduate students and mostly ignored graduate students' experiences with CBL (Goodhue, 2017). Integrating CBL into graduate education has gained attention in the past decade because CBL allows graduate students to inculcate professional values and ethics, situate academic knowledge and understanding in contexts, and practice academic citizenship through serving communities with disciplinary knowledge and skills (Beckman et al., 2009; Goodhue, 2017; Thompson \& Davis, 2013).

In a North American higher education context, about 50\% of the graduate student population are international students (Canadian Bureau for International Education, 2018; Institute of International Education, 2018; Okahana \& Zhou, 2019). This significant percentage means that CBL programs and praxis at the graduate level need to be responsive to international students' needs to achieve greater inclusion and excellence. Existing CBL programs, research, and praxis that are responsive to international graduate students' needs are limited and overlooked (Sharma, 2019). A better understanding of international graduate students' experiences in CBL is critical for addressing this gap and for making graduate education more inclusive and responsive to all, including international students.

International students' needs and objectives for graduate education differ greatly from that of their domestic counterparts. In addition to obtaining an advanced degree for personal and professional development, developing a global mindset; improving cross-cultural awareness and communication skills; learning about peoples, cultures, and communities in host countries; and exploring immigration opportunities are also significant learning objectives during education abroad (Kim \& Kwak, 2019). Both formal and informal education on campus and in communities offer learning opportunities for international graduate students to achieve these desired objectives and, therefore, are equally important for international graduate students. For the purpose of this article, CBL refers to both the credit-bearing educational experiences—also known as service-learning — and other community volunteer experiences that are not tied to a specific course or program. This article reports a mixed methods case study examining the impact of CBL on international graduate students at a Canadian public university. Beginning with a brief review of the research context, methodology, and methods, the article reports findings on students' perceptions of CBL and the impact of CBL on international graduate students in five areas: academic, sociocultural, personal, professional, and global citizenship development. The article then discusses the implications for higher education institutions (HEIs) and offers recommendations on CBL program development in graduate education and future research possibilities. Findings shed light on the pitfalls and opportunities of enhancing the inclusivity and responsiveness of a CBL program and praxis in a HEI with a large number of international graduate students.

\section{International Students in Global Higher Education}

Globalization has had great impact on HEIs in the global context during the past decade. One of the most striking phenomena is greatly increased cross-border student mobility, intensified by the General Agreement on 
Trade in Services (GATS) of the World Trade Organization (WTO), an international treaty that formalizes the market process and procedures for education as a global trade service, which has accelerated the internationalization of higher education in many countries (Altbach \& Knight, 2007; Jin, 2006; Vavrus \& Pekol, 2015). More and more students worldwide choose to study abroad each year because education abroad experiences have multifaceted long-term impacts on individuals, including deepened personal learning and development, expanded career and professional opportunities, enhanced educational outcomes, increased understanding of world issues, transformed worldviews and values, and increased interests in global engagement (Paige et al., 2009).

An international student is defined as an individual who has physically crossed an international border between two countries with the objective of participating in educational activities in a destination country that is different from their country of origin (Nita et al., 2017). Of the 4.1 million students who chose to study abroad in another country in 2016, most came from developing and emerging countries where an educated and intercultural population is a key driver for economic prosperity and social progress (CBIE, 2018; IIE, 2018). HEIs in many countries have a more complex relationship with the rest of the world. International students reinforce this complex relationship through their impact on the host institutions and communities in different facets: social, cultural, economic, environmental, educational, and political (Proctor \& Rumbley, 2018).

International student contributions to the host countries and institutions are multi-dimensional (CBIE, 2018; Hegarty, 2014; IIE, 2018). The economic contributions of international students are reflected not only in tuition fees, ancillary services such as accommodation, hospitality, and increased travel and tourism but also through the roles they play in strengthening transnational connections and global engagement and the rich cultural and intellectual resources they bring to academic environments, workplaces, and communities (Burnett, 2015; Tran \& Gribble, 2015). International students also play important roles in research development and technological innovation as well as in promoting global social justice, greater cross-cultural understanding, and sustainable development (Chellaraj et al., 2008; M. Guo-Brennan \& L. Guo-Brennan, 2019; Hayden et al., 2015). Creating welcoming environments and identifying inclusive program practices are critical for increasing inclusion and equity of teaching, learning, and services in HEIs (Dunn \& Olivier, 2011; Tran \& Gribble, 2015).

\section{Needs and Challenges of International Graduate Students}

Living and studying in an environment that is culturally, educationally, and socially unfamiliar, international students in graduate programs have needs and challenges that are different from those of domestic graduate students. Many factors affect international graduate students' success and satisfaction with their study abroad experience. These include the capacity of host institutions and communities to be welcoming, the challenges of blending academic responsibilities with personal and social transitions into a new country, adjusting to new academic environments and expectations, and developing confidence (Andrade, 2006; M. Guo-Brennan \& L. GuoBrennan, 2019). International graduate students reportedly have unique needs and challenges in four areas- 
academic, sociocultural, financial, and professional-and addressing these needs and challenges in culturally appropriate ways is critical for international students' success.

\section{Academic Needs}

Using a second or foreign language to navigate and balance the graduate academic demands in a new educational environment, many international graduate students experience ambiguity and stress during their graduate studies. The level of stress is affected by various factors, including the connection between graduate curricula and international students' prior knowledge and experiences, students' familiarity with academic policies and regulations, cultural differences in learning styles and expectations, and student-faculty academic relationships (Guo \& O’Sullivan, 2012; Knutson, 2011; Li \& Tierney, 2013).

Critical thinking and interpersonal communication skills are crucial to graduate students' academic performance and success. However, language and the lack of contextual understanding of academic content are significant impediments for international students to express thoughts and opinions critically, creatively, and confidently in academic work and learning processes (Guo, 2012; Myers-Walls et al., 2011). Having limited time and opportunities to develop a contextual understanding of the disciplinary knowledge and professional practices embedded in graduate courses and curricula, international graduate students' academic needs and challenges are often interpreted as a lack of criticality or academic competence (O’Sullivan \& Guo, 2010; Paul \& Elder, 2014; Thomson et al., 2006).

\section{Psychological and Sociocultural Needs}

Many international students experience psychological stress and social isolation due to cultural differences in social and academic interactions (Baba \& Hosoda, 2014; Kagitcibasi, 2007; Li \& Tierney, 2013; Lieber et al., 2001; Mallinckrodt \& Leong, 1992; Sandhu, 1994). These difficult experiences can result in mental health and psychological problems such as psychosomatic complaints, depression, anxiety, and paranoid reactions (Lee \& Rice, 2007; Mori, 2000; Ying \& Liese, 1991). For many international graduate students, pressures associated with family responsibilities add to their acculturation and sociocultural concerns (Myers-Walls et al., 2011; Yellig, 2011). Helping international students adjust socially and culturally through intentional program design

and praxis is not only desirable but also critical for international students' success and satisfaction in a graduate program (Brauss et al., 2015).

\section{Financial Needs}

Financial challenges are a substantial source of stress for many international graduate students due to higher tuition fees, limited scholarships or loans, and restrictive student visa policy and regulations (Brauss et al., 2015; Mori, 2000). The availability of opportunities for gaining professional competencies and experiences through 
a graduate program can be a defining factor for international students' decision on a graduate program because many graduate students actively seek employment opportunities in their home or host countries after graduation (CBIE, 2018).

\section{Professional Needs}

Assisting graduate students in forging social and professional connections with peers and professional communities is critical to successful outcomes in graduate education. These connections can provide graduate students with information on effective work-study skills and practices, job prospects, funding opportunities, research collaborations, and academic conferences, which are important for future employment or advanced graduate studies. International graduate students are often challenged to form meaningful professional relationships with peers, instructors, and community members as they deal with the transition to a new social, cultural, and academic environment; language barriers; cultural differences in social interconnection; unfamiliarity with social and cultural norms; and a lack of opportunities to develop cross-cultural understanding and awareness (Brauss et al., 2015).

\section{Research Context and Objectives}

This research was conducted in Canada, the country receiving the fourth highest number of postsecondary international students after the United States, United Kingdom, and China (CBIE, 2018). From 2010 to 2019, the number of international students in Canada's higher education sector increased by $119 \%$, and about $43 \%$ of international students were enrolled in graduate programs (CBIE, 2018). This broader trend of increasing numbers of international students is reflected in large and small universities and colleges across the country.

Participants of the study were enrolled in a two-year Master of Education (MEd) graduate program specifically designed for international students and educators. Through integrating global perspectives into curriculum and instruction, this program aims to advance students' understanding of education in global contexts and prepares them to work effectively in all types of educational settings influenced by global economic, political, social, and technological development. CBL is integrated into a number of academic courses in this graduate program as opportunities for students to understand important trends, issues, and praxis in education from international and comparative perspectives. Students participate in CBL in diverse educational settings and communities, classroom teaching observations, leadership observation, collaboration with domestic students in face-to-face and online environments, service and reflections at various workplaces, action research projects in local communities, personal reflection on theory and practice, and cross-cultural training on job search and application strategies. Table 1 highlights the CBL components embedded in the graduate program.

Instructors in the program frequently heard international students' anecdotal comments that they really enjoyed and appreciated the CBL opportunities through their graduate studies. However, to what extent CBL contributed to international students' learning and development remained unclear. A deeper understanding 
Table 1

Community-Based Learning in the Master of Education (MEd) with Global Perspectives Program

\begin{tabular}{|c|c|}
\hline Course title & Description of community-based learning (CBL) \\
\hline Graduate seminar & $\begin{array}{l}\text { Students observe teaching, learning, and leadership in various educational settings and develop } \\
\text { comparative perspectives on curriculum and pedagogy }\end{array}$ \\
\hline Workplace learning \& leadership & $\begin{array}{l}\text { Students are placed in informal and formal educational settings and community organizations } \\
\text { to gain experiential knowledge and understanding of the organizational culture, behaviors, } \\
\text { and leadership in action. Students are expected to develop their cross-cultural understanding } \\
\text { and communication skills through this course. }\end{array}$ \\
\hline Educational leadership & $\begin{array}{l}\text { Students examine the field of educational leadership through shadowing leaders and admin- } \\
\text { istrators in educational settings. Students explore models of effective leadership through } \\
\text { case studies and simulation and learn to become leaders who make an impact on creating } \\
\text { effective educational environments. }\end{array}$ \\
\hline Action research & $\begin{array}{l}\text { The course aims to develop students' action research and academic writing skills. Students } \\
\text { are encouraged to explore and identify research topics based on their workplace learning } \\
\text { outcome and placements. }\end{array}$ \\
\hline Career development services & $\begin{array}{l}\text { A series of workshops to help international students understand the regional labor context, job } \\
\text { market, workplace culture, cultural similarities and differences in job searching, or gain skills } \\
\text { in networking, job preparation, and interview. }\end{array}$ \\
\hline
\end{tabular}

of the impact of CBL on international graduate students' academic, sociocultural, personal, and professional development is critical for all stakeholders in this program, including students, faculty, the institution, and the community organizations. The purpose of this study was to gain a deeper understanding, specifically by addressing three questions:

1. What are international graduate students' perceptions about CBL?

2. What is the impact of CBL on international graduate students?

3. What factors influence international graduate students' engagement in CBL?

\section{Methodology and Methods}

\section{Case Study Research Design}

A case study approach was adopted because the methodology enabled a focus on the particularity and complexity of a single case to understand an activity and its significance (Creswell, 2014; Harrison et al., 2017; Stake, 1995). This approach was appropriate for this study because it allowed the research team to obtain comprehensive and in-depth insight into a specific graduate program infused with CBL and cast light onto the unique conditions, challenges, and experiences of international students in CBL. This research design allowed use of multiple sources of information and data collection, which laid a foundation for gaining a deep understanding of international graduate students' experiences and perspectives on CBL. 


\section{Data Collection}

Data collection methods included document analysis, an online survey (Appendix A), and individual interviews (Appendix B). The document analysis focused on the broader social, political, cultural, and economic contexts of CBL in global higher education, institutional policy on CBL, and the CBL curriculum and strategies adopted by this MEd program.

The online survey (Appendix A) developed for this study consisted of 39 items, including 6 open-ended questions about participants' country of origin, language, program of study, registration status, and the setting where they participated in CBL experiences; 29 Likert scale self-report statements related to the impact of CBL on their development in five distinctive areas: academic, sociocultural, personal/professional, civic engagement and global citizenship, and challenges and suggestions for CBL; and 4 Likert scale statements with general comments on CBL in graduate studies. These items were developed based on an extensive literature review on CBL and consolidated by research team members from multiple disciplinary fields in higher education, including international education, family sciences, language education, and public policy. Thirty-three items were measured through a Likert-type scale with six response options (Strongly Disagree, Disagree, Not Sure, Agree, Strongly Agree, Not Applicable) to measure participants' level of agreement with each statement.

Survey items related to academic development asked participants to share their opinions on the impact of CBL on their academic work and learning; opportunities to apply newly acquired skills and knowledge in reallife situations; understanding of course content; English communication skills; multiple perspectives/values/ beliefs; and skills in teaching/mentoring, critical thinking, and problem solving.

Survey items related to sociocultural development asked participants to share their opinions on the impact of CBL on fostering cross-cultural awareness and understanding, meaningful social and professional relationships, cross-cultural communication skills, experiences with new cultural traditions, understanding of diverse cultures in communities, and understanding of sociocultural issues in their host community and country as well as root causes of these issues.

Survey items related to personal/professional development asked participants to share their opinions on the impact of CBL on self-awareness of their own culture and biases, interpersonal skills, ability to work in intercultural contexts, leadership skills, career interests and plans, post-graduate career plans and immigration, adaptation skills, and open-mindedness.

Survey items related to civic engagement and global citizenship asked participants to share their opinions on public service, civic participation, their own beliefs in making a difference, responsibilities and contributions toward the host community and country, understanding and commitment to global justice issues (e.g., poverty, equality, discrimination), commitment to addressing social issues and problems, confidence in making a positive impact on communities, value of volunteerism and civic participation, opportunities to share international perspectives with local communities, and responsible global citizenship.

Survey items related to participants' perceptions of CBL asked participants to share their opinions related to graduate programs with CBL opportunities, the likelihood of engaging in community services after graduation, 
challenges and difficulties in CBL participation, and their suggestions for improving CBL for graduate students.

At the end of the survey, all participants were asked whether they would like to participate in individual interviews to share their perceptions, experiences, and recommendations. Ten international graduate students volunteered and participated in follow-up interviews that gave participants the opportunity to use specific examples to elaborate on their survey responses and provide additional insights on CBL. All interviews were conducted on campus, and each lasted about one hour. As a majority of international students were Chinese, we gave participants the option to be interviewed in Chinese. Interviews were guided by prepared questions (Appendix B) and focused on participants' perspectives, experiences, questions, and suggestions about CBL. All interviews were audio recorded, translated as needed, and fully transcribed. University ethical guidelines for research were strictly followed through the data collection process.

\section{Participants}

As the purpose of this case study was to understand international graduate students' experiences and perceptions on CBL within a specific graduate program with embedded CBL components, participants of this study were not randomly selected. Instead, we purposely invited the graduated, current, and incoming international graduate students in this specific international MEd graduate program. Research invitations were sent through a mailing list to approximately 70 students. Social media and posters were also used to reach those who had been admitted into the program. Within a period of four weeks, 58 students responded to the online survey, a response rate of $83 \%$. Thirty-four participants completed the survey with 14 individuals responding to the demographic questions on the survey without giving any responses to the 33 main survey items. Therefore, these 14 survey responses were not included in the data analysis. A few incoming international graduate students enrolled in a graduate study preparatory program had not yet engaged in CBL opportunities in the graduate program, but their survey responses related to volunteering activities were included in the data analysis because they reported that these activities allowed them to improve English communication skills and learn about peoples and cultures in host communities - two important learning objectives of international graduate education.

\section{Data Analysis}

As most of the survey items were designed to seek participants' opinions and perceptions on CBL and the impact of CBL on their development in the above-mentioned five distinctive areas, the ordinal data generated by the Likert-type statements was filtered by cross-tabulating the statements under the five major themes/areas and was analyzed by grouping participants' positions in percentages. For instance, under the theme Impact of CBL on Academic Development, the statement "CBL has a positive impact on my academic work and learning" received 10 Strongly Agree, 15 Agree, 5 Not Sure, 0 Disagree, 1 Strong Disagree, and 2 Not Applicable. We categorized these responses and concluded that 75\% (25/34) of participants perceived that CBL had a positive impact on their academic work and learning. SPSS software was used to conduct cross tabulation and visualization of data 
generated from 34 completed surveys. During individual interviews, we invited participants to provide specific examples of the positive and negative impact of CBL on their development in five distinctive areas. Interview transcripts were coded and analyzed using NVivo 11 software to gain richer and deeper insights on each statement and theme identified. With data collection complete, three members of the research team read each transcript and independently developed codes that were then discussed with two other team members. This resulted in a list of themes that were then used to code the transcripts.

Data collected from the surveys and interviews validated the other data and created a solid foundation for gaining a comprehensive understanding of the impact of CBL experiences on international graduate students. The validity, credibility, and trustworthiness of the findings were ensured by data triangulation and checking by members of the multi-disciplinary research team.

\section{Findings and Discussion}

\section{International Students' Perceptions of Community-Based Learning}

A majority of survey respondents (68\%) engaged in CBL through graduate courses related to educational leadership, curriculum and pedagogy, and workplace learning, whereas 32\% of survey respondents only reported community engagement and volunteering experiences because they had not engaged in CBL through the graduate program by the time of the study. About half of all participants reported non-credit bearing community engagement and volunteering experiences because these activities allowed them to develop greater crosscultural awareness, practice cross-cultural communication, and expand perspectives on peoples, cultures, and communities-objectives and outcomes similar to the CBL opportunities embedded in the graduate program. For this reason, a broader CBL concept was adopted in data analysis and reporting as both credit-bearing learning and non-credited community engagement and services enabled participants to achieve their desired global learning outcomes.

Participants' CBL activities occurred in three sectors: higher education (35\%), public and nonprofit sector (41\%), and private sector (24\%). Higher education settings included the Chaplaincy Centre, international office, student affairs office, and Seniors College. Off-campus settings included schools, government offices, business organizations, nursing homes, childcare centers, the Humane Society, newcomer settlement agencies, and faith-based organizations. A large majority (85\%) of survey respondents perceived CBL as valuable experiential learning and clearly indicated that more CBL opportunities in graduate education would be very beneficial. A substantial percentage (79\%) of survey participants stated that CBL should be an integrated component of all graduate programs and suggested curriculum integration as the best approach to ensure students' greater participation. Many indicated CBL opportunities in graduate education were highly beneficial to international graduate students. As one participant commented: 
If you can make it (CBL) more obvious in graduate program, more students will be enrolled in this program. International students would like it. The benefits are pretty obvious-they meet people, improve language skills, learn from daily life. (Participant 3)

\section{Impact on Academic Development}

\section{Deepened Understanding of Disciplinary Theory and Practices}

The majority of survey respondents (74\%) indicated that CBL served as a critical venue for their academic enhancement, such as academic language proficiency, English oral communication skills needed in classroom learning, and situating educational theories and concepts in appropriate contexts. For many, the contextual understanding of academic concepts, theory, or research served as a stimulus for meaningful discussions and engagement in classrooms. One participant explained how CBL helped her gain a better understanding of Indigenous education in Canada:

We had a blanket activity. I got the chance to listen to indigenous music and enjoyed their dance. It was interesting and fun. It helped me know more about the indigenous history, culture and current situations

in Canada.... I really respect and appreciate the indigenous culture now. (Participant 1)

CBL allowed participants to understand core educational concepts in authentic contexts. For those who were not familiar with core concepts and issues related to education—such as instructional leadership, studentcentered pedagogy, curriculum, hidden curriculum, teacher identity, school development and planning, and action research-CBL offered opportunities for them to make sense of these issues in context. Another participant commented on how graduate courses integrated with CBL enhanced his academic performance:

The Graduate Seminar course had a huge impact on my academic study. Through field visits in this course, I learned about the provincial educational system, observed teaching learning activities in classrooms. This experience gave me new ideas on relevant research topics. (Participant 4)

Other participants reported that CBL allowed them to observe how professional communication and relationship building was conducted in workplace settings. Reflecting and comparing the similarities and differences between the educational systems and workplace cultures in Canada and those of their home countries broadened their perspectives on education, culture, and communities. 


\section{Improved English Language Proficiency}

Language barriers not only are a major hindrance to international students' academic performance and development but also add psychological stress to social interactions and connections (Bailey, 2010; Cowley \& HyamsSsekasi, 2018; Medved et al., 2013; Yeh \& Inose, 2003). A significant proportion (82\%) of all survey respondents in this study confirmed that they practiced and improved English communication skills during CBL.

The first benefit (of CBL) is improving my language communication skills and fluency. If I can hear clearly what the person says, I can totally understand it. But if the locals speak too fast or have a strange accent, I feel frustrated. When I heard or read something that I'm not familiar with, I took notes and checked them later. I improved my English this way. (Participant 2)

\section{Strengthened Research Skills}

Learning to conduct research is a critical learning objective of graduate education. While graduate research courses help international graduate students understand research design and procedures, CBL created opportunities for international graduate students to identify important research topics that not only dovetailed with their interests but also were relevant to both local and international communities. Some students reported that CBL provided them with research opportunities to explore issues and topics such as early childhood education from comparative perspectives and expanded their research knowledge and skills on topics of interest.

\section{Improved Teaching/Mentoring Skills}

Teaching and mentoring skills are important learning outcomes and an essential professional competency for graduate students in the Master of Education program. Many survey respondents (69\%) agreed that their teaching or mentoring skills were improved through CBL experiences. Reflecting on her experiences of teaching seniors, a participant commented that CBL allowed her to develop a better understanding of principles and instructional methods appropriate to adult learners:

I once taught a computing technology class to a group of seniors. I found that seniors don't like to be taught directly ... so I slowed down the instruction, lowered my voice and guided them to learn by themselves. Once they knew how, they remembered the content better. (Participant 5) 


\section{Impact on Sociocultural Development}

\section{Enhanced Cross-Cultural Awareness and Understanding}

Almost three-quarters of the survey respondents (74\%) confirmed that CBL allowed them to develop crosscultural awareness and understanding. One participant discussed how CBL expanded her understanding of Canadian culture:

During the language learning exchange sessions, I sometimes asked my learning partners questions about the local culture and customs, such as "If somebody invites me to their home to have a meal, what should I say if I don't want to go?" "If I am invited to a meal at someone’s house, do I need to bring gift?” My learning partner really helped me better understand how to interact with people from local communities. (Participant 9)

Other students reported increased awareness of religious traditions and beliefs different from their own. In discussing learning about the organizational structure and the architectural design of churches as well as the function of the campus chapel, a participant used the Chaplaincy Centre on campus as an example to illustrate the importance of an inclusive environment for students with diverse religious backgrounds, including Catholic, Baptist, Islamic, Buddhist, and Taoist.

CBL offered international students' ample opportunities to participate socially, economically, politically, and culturally within the host community and created cross-cultural social environments they could not experience on campus. CBL helped most survey respondents (88\%) understand the diversity not only in cultures but also in learning needs and styles. One participant shared her observation on English language learners' different learning styles:

When I taught LINC (Language Instruction for Newcomers in Canada) class, I had students from the Middle Eastern countries and China. I noticed that the Middle Eastern students would rather speak English when they stayed together, but Chinese students would prefer to speak Chinese when they stayed together. This made me realize people from the different countries learn English differently. (Participant 6)

\section{Increased Social Capital}

Social capital refers to the resources embedded in people's social networks and wider social connections. It helps individuals gain access to resources, information, and support and involves reciprocity and connections that are governed by a high degree of trust and shared values (Coleman, 1988; Portes, 2000). Developing and maintain- 
ing sustainable social capital can increase international students' sense of belonging but is challenging (Poteet \& Gomez, 2015), particularly for Chinese international students who heavily rely on the Chinese online social networking app WeChat for bridging and bonding social capital (Yuan \& Izuma, 2018).

More than three-quarters (79\%) of survey respondents stated that CBL helped them tackle the challenges encountered in a new country and unfamiliar environment by building meaningful social and professional relationships, developing cross-cultural communication and leadership skills, and expanding their awareness of cultural traditions and beliefs. In addition, most survey respondents (88\%) noted that CBL provided new opportunities for them to expand their social networks, access more public services, become more aware of community events, and increase their interaction with local community members.

University students with increased exposure to diversity are more likely to have higher scores on social agency, critical thinking disposition, and academic self-confidence (Laird, 2005), and this aligned with the majority of survey respondents (68\%), who indicated that CBL expanded their understanding of social issues and root causes. Observing how issues related to diversity, globalization, and global interdependence were manifested in local communities, students became more open and appreciative toward the differences of values, lifestyles, and worldviews.

\section{Impact on Personal and Professional Development}

\section{Personal Development}

The contrasts and differences in home and host communities provided ample opportunities for international students to examine their personal strengths and weaknesses. Most survey respondents (85\%) reported a deepened understanding of their identity and culture through CBL. In addition to personal values, career plans, worldviews, traditions, and lifestyles, social justice was reported as a topic of increased understanding.

After having the chance to observe local families' unique lives and cultural practices, most students felt motivated to reflect on their own perspectives and biases, and 60\% reported that their awareness of diversity and sociocultural exclusion in society had greatly increased. Some shared that their feelings of exclusion and discrimination allowed them to critically examine factors affecting their educational experiences, such as self-esteem, social competence, causes of social/psychological isolation, and perceived discrimination, as one participant commented:

Once I was discriminated by a person in the public library. Since that experience, I became curious about the reasons behind it (discrimination) and started reading social reports. I learnt (that) people who lack awareness of social issues are more likely to judge others based on their own prejudiced opinions. (Participant 1) 
Adaptability, openness, and confidence are important attributes for citizens living in a globally interconnected world and society (OECD, 2019). A majority (71\%) of survey respondents confirmed personal development in this area. A participant shared her reflection on this aspect: "I contributed my time and put my skills into practice. This contribution was appreciated by the community. I gained trust and appreciation. I also felt encouraged and confident through helping others" (Participant 10).

During their studies, international graduate students often experience tremendous stress that can be the result of several common issues, such as "adjustment to living in two cultures, feeling overwhelmed, language difficulty, feelings of isolation, financial stress and marital stress" (Myers-Walls et al., 2011). A participant touched on this when asked about the benefits of CBL:

One (benefit) is improving my social skills to communicate with others. Another one is helping me relieve my stress from my academic learning. It also helps me find balance, find a new hobby, and a new friend who has the same interest and can help each other. (Participant 1)

\section{Professional Development}

Two-thirds of the participants (68\%) reported that CBL enhanced their skills in leadership, interpersonal communication, critical thinking, and problem-solving. International students perceived these skills as extremely important because they are fundamental in effective social interaction in the communities and workplaces. Seventy-four percent of respondents stated that CBL helped them clarify their career/life plans.

For an early childhood educator, both professional and language skills are important because infants or toddlers are at the age of learning language. I don't want to become a teacher here (early child center) because of my language skill. This (CBL) experience gave me more chances to look at the advantages and disadvantages I have for future jobs. (Participant 9)

Canada actively recruits international students as skilled workers through its post-graduate work permit program for international students. More than half of the survey respondents (62\%) mentioned that CBL experiences would be beneficial for their post-graduate work permit applications, as the work experiences are related to the field of their graduate education. CBL also increased participants' management and organizational skills, such as event planning, environmental scanning, legal compliance, risk management, use of technology, and interpersonal relationships. Having the opportunities to shadow educational and community leadership in workplaces allowed international students to develop new perspectives on effective leadership and to connect leadership theory with praxis.

Other transferable skills international graduate students developed through CBL include increased crosscultural competency, new perspectives on professional standards and ethics, and enhanced capacity to apply disciplinary knowledge and understanding in real-world settings. These findings were reflected in other CBL 
studies (Matthews et al., 2015; Wagner, 2008). In addition to these benefits, international graduate students in this study also gained problem-solving and collaboration skills. One participant shared her view on this aspect:

I developed problem-solving and collaboration skills. In the past, if I have a question, I usually find the answer in the textbook, ask the professor, or Google it. At the workplace, there are more solutions to a problem. I don't have to do it all by myself. Many colleagues can give me ideas and suggestions. Company manual also lists questions and solutions, or I can ask my supervisor for help. (Participant 4)

\section{Fostering Global Citizenship}

Global citizenship refers to global awareness, responsibility, and accountability as reflected in a citizen's local actions in a globally interconnected world (L. Guo-Brennan \& M. Guo-Brennan, 2019). The majority of international students in this study believed that they should contribute to their host community and country during study abroad. All participants indicated that they became more appreciative about volunteerism and civic engagement. Many (70\%) expressed strong interest in public service and civic participation, as they felt sharing perspectives and experiences with host organizations and communities was rewarding.

International students perceived themselves as active citizens in both their host and home countries, and a great majority (85\%) of survey respondents confirmed a deepened understanding of and commitment to global justice issues such as poverty, equality, and discrimination. Participants were empowered to take a more active role in addressing issues relevant to their host communities because of their increased awareness of issues relevant to the local community, such as an aging population, food insecurity, newcomer integration, employment and unemployment issues, and environmental sustainability.

\section{Barriers in Community-Based Learning Participation}

Half of the survey participants (50\%) reported that their international student status presented challenges and difficulties for CBL. Through interviews, all participants were invited to talk about the challenges and barriers that they had experienced in CBL activities. Common barriers and challenges faced included language barriers, lack of reliable transportation, cultural disorientation, conflicts with class schedule, cultural differences in interpersonal relationships, lack of personal motivation, and the policy restrictions on student visas. When asked about the challenges he experienced with CBL, one participant with a bachelor's degree in English Linguistics and Literature reported language barrier and personality issues:

Although I was a teacher for many years, I still felt too shy to communicate, especially when there is a misunderstanding during the conversation. When I can't explain clearly, I feel upset and discouraged. This is not a problem in China. But in Canada, I cannot speak English or French smoothly. So sometimes I felt frustrated. (Participant 10) 
Cultural differences of social and interpersonal interaction could also be challenging for international graduate students:

I understand the local culture, but I still feel difficult to get involved in their activities. I do not like parties with loud music and alcohol. I rarely participated in this kind of social event before and don't feel comfortable in this type occasions, especially in the evenings. But if I don't immerse myself in the local culture, it will be barrier for further social interaction. (Participant 3)

This response indicates that CBL allowed international students to become more aware of social, cultural, and interpersonal similarities and differences between home and host communities and countries-the cognitive growth and knowledge acquisition in sociocultural learning (Vygotsky, 1978).

For some graduate students, age can be a barrier in accessing CBL opportunities.

I am a member of the University Rotary Club, but the Club is for students under the age of 30. I am 28 now and will become disqualified in two years. Another NGO on campus also has age limit. ... I don't feel comfortable or confident to join organizations or membership with age requirement because I might be the oldest one in the group. (Participant 5)

Although only one participant specifically talked about age as a barrier, this issue cannot be ignored in CBL planning and praxis for graduate students for several reasons. First, students in graduate programs are likely older than those in undergraduate programs, and ensuring they are not discriminated in CBL participation is important for inclusive CBL praxis. Second, ensuring that students' roles and tasks in CBL are appropriate to their age is a critical element of high-quality CBL (Jacoby, 2015). In addition, international graduate students often rely on public transportation to get to communities. The availability of public transportation is often a defining factor in their decisions on the location and time of CBL participation.

Despite challenges and barriers, a great majority of survey participants (83\%) stated that they would love to have more CBL opportunities during graduate education. During interviews, most participants stated that experiential learning in communities provided opportunities to apply and practice cross-cultural social, communication, and collaborative learning skills that were missing from in-classroom learning or from books. One student specifically shared his thoughts on this:

Through CBL, I learned new things from others. My language buddy shared with me his experiences working in a nonprofit organization for kids with special needs. . . Before (graduate studies), I already know the concept of inclusive education. Through my language buddy, I learnt what they did to make education inclusive. This is a very meaningful research topic. (Participant 6) 


\section{Implications for Higher Education Policy and Praxis}

As public institutions, HEIs worldwide strive to harness the intellectual and human resources of students and faculty to make contributions to the social and economic development of societies and communities (Shek \& Hollister, 2017). HEIs that are serious about engaging with broader communities and involving faculty and students in civic problem-solving must support and institutionalize CBL so that it is available to all students. They also need to be aware of the pitfalls as well as opportunities to achieve greater outcomes (Dostilio, 2014; Eyler, 2009). Findings from this study have several important implications for CBL in higher education.

\section{Opportunities for Greater Engagement and Inclusion}

Rooted deeply in the democratic principles of justice and opportunity, inclusive practices in higher education are critical for improving students' learning and engagement. International students are uniquely positioned to provide important insights on diversity issues related to race, ethnicity, citizenship, religion, cultures; however, they are not always given opportunities to share perspectives and experiences related to these issues (Lillyman \& Bennett, 2014; McNally, 2018). CBL allows international graduate students to authentically engage in critical scholarly conversations and inquiries on diversity and inclusion. CBL connects classroom learning to students' professional development needs, helps them develop civic professionalism through active community engagement, and reflects the principle of equal quality education opportunities for all in higher education (Deller et al., 2015).

Engaging international students in CBL requires HEIs to employ institution-wide initiatives through which all stakeholders share strategic direction, procedures, and resources. Faculty or staff involved in CBL program and curriculum development are often engaged in administrative functions of developing and sustaining campuscommunity partnerships and spend hours assessing students' learning and engagement, which often results in increased workload and time commitment. This type of expertise and commitment are invaluable and need to be recognized in tenure and promotion policies and procedures to enhance curriculum/program integration and institutionalize faculty engagement (Foster, 2010; Moore \& Ward, 2010).

Sustainable international graduate programs require welcoming and inclusive environments, policies, and praxis. CBL contributes to the sustainability of graduate education and increased cross-cultural education when the societal, community, and institutional environments and cultures are intentionally built to include members with diverse linguistic, ethnic, and cultural backgrounds (M. Guo-Brennan \& L. Guo-Brennan, 2019). Creating an open and safe environment for students to experience and develop diverse perspectives is an important strategy for developing global citizenship and inclusive communities (M. Guo-Brennan \& L. Guo-Brennan, 2019). Through CBL, international students have authentic opportunities to experience and reflect on social justice and global issues, such as poverty, racism, discrimination, inequality, religious diversity, human rights, citizenship, and politics. As valuable opportunities for developing students' multiple perspectives, these global and social issues need to be considered and integrated into higher education leadership development, policy-making, 
program and curriculum development, instruction, assessment and evaluation, and student services (Banks \& Banks, 2019; M. Guo-Brennan \& L. Guo-Brennan, 2019). Helping students, faculty, staff, and partner organizations appropriately navigate these common issues in cross-cultural CBL environments through institutional guidelines and professional development services and training can mitigate negative impacts on both individuals and organizations.

\section{Implications for Graduate Programs}

\section{Faculty Support and Recognition}

High-quality CBL for graduate students relies on the fit between the academic goals of the program and community-based opportunities as well as on thoughtful integration of CBL into courses and curriculum (Clayton et al., 2013). As international students' needs, expectations, and challenges are different from those of domestic students and integrating CBL into course design takes time to successfully plan, the workload and expertise of faculty cannot be underestimated or taken for granted (Sharma, 2019). In addition to developing course syllabi with clearly defined learning objectives and activities, faculty members who teach a CBL course or conduct research into CBL are often engaged in a variety of activities that strengthen partnerships with community agencies, including visiting community organizations, addressing student issues at workplaces, effectively engaging community agency staff as co-educators, and ensuring student commitment to community partners. Successful CBL for international students requires strong institutional support for this level of community engagement as well as culturally competent faculty and staff.

\section{Alignment with Immigration Policy and Requirements}

A nation-state's immigration policy and regulations and international students' temporary resident status in the host countries have significant implications for integrating CBL into graduate education. Faculty and student awareness of the regulations related to student visa and permanent residency are particularly important for providing international graduate students with $\mathrm{CBL}$ opportunities that enhance their sociocultural connections and employability while maintaining legal status during the graduate program. In some countries, such as Canada, Australia, and New Zealand, the immigration policy related to international students and the post-study work permit or visa programs create space and opportunities for HEIs to integrate CBL components into international graduate education while responding to regional and national needs to attract a highly skilled workforce. This broader policy environment has not only greatly increased international student enrollment in higher education but also provided opportunities to explore innovative international graduate programming in HEIs. 


\section{Critical Questions on Community-University Partnerships}

This study clearly indicates that structured CBL opportunities and experiences are desired by international graduate students; however, cultural differences, different social norms, lack of confidence and skills in language communication, and logistical reasons present challenges in developing democratically engaged partnerships that provide meaningful and culturally responsive CBL to international students. In some instances, this results in international students' exclusion from activities and venues in which domestic students commonly establish peer relations and professional networks, such as Friday night pub gatherings, department holiday parties, and social outings (Gresham \& Clayton, 2011; M. Guo-Brennan \& L. Guo-Brennan, 2019; Hanassab \& Tidwell, 2002). Forging positive sociocultural and professional connections among faculty, students, and partner organizations helps overcome the limitations caused by these factors (Gresham \& Clayton, 2011).

To ensure reciprocity and meaningful engagement in CBL, it is imperative that democratically engaged community-university partnership leadership make space for inclusion, deliberation, and transparency (Dostilio, 2014). Who plays the role of partnership leadership? What are the roles of students, course instructors, program directors, and deans in this process? What type of partnership leadership is preferred by the CBL stakeholders (one person or collaborative leadership)? What processes and skills are necessary to steward a democratic engagement process? How can we most effectively engage students in critical reflection on the linguistic, political, and sociocultural needs and challenges through curriculum and learning activities? To what extent is cross-cultural learning and interaction mutually desired by students and partner organizations? How can we ensure that the cognitive, socioemotional, and behavioral dimensions of CBL contribute to disciplinary theory and inquiry in graduate education? Robust scholarly conversations on these questions need to be deliberately conducted when integrating CBL into international graduate education.

\section{Discomfort as a Critical Community-Based Learning Pedagogy}

In CBL, international graduate students often encounter uncomfortable experiences that are associated with lack of language proficiency, difficulties in effective cross-cultural communications, racism and discrimination, beliefs and values, social and cultural habits, and power relations. On the one hand, these discomforts can generate feelings of exclusion, isolation, confusion, frustration, anxiety, or fear (VanLeeuwen et al., 2019). On the other hand, discomfort can be used as a critical pedagogy to provide transformative learning opportunities as it allows international students to confront their own emotions and identify through critical reflection on events, cultures, beliefs, social habits, and normative practices the ambiguities, asymmetries, contradictions, and cultural traditions that perpetuate injustice in communities and societies (Boler, 1999; Mezirow, 1997; Sharpe \& Dear, 2013; Zembylas \& McGlynn, 2012).

In the process and objective of critical reflection, faculty can use discomforts as teachable moments for stu- 
dents to explore the root causes of discomfort; develop awareness of bias and assumptions of their own and others; expand frames of references in cognitive, socioemotional and behavioral dimensions; and develop a greater understanding of personal strengths and limitations (Ash \& Clayton, 2009; VanLeeuwen et al., 2017; Whitney \& Clayton, 2011). This type of critical reflection provides space for students to recognize and understand the ethical, political, economic, and social conditions that impact their community and their experiences-a necessary step in engaging in open, appropriate, and effective interactions across cultures (OECD, 2019).

\section{Limitations and Recommendations}

This study has several limitations. First, the study was limited by a small sample size. The case study was conducted in an international graduate education program infused with CBL at a small Canadian public university, so the sample size is limited to the participants in the program. Findings of the study are closely tied to the context of the study and may not be transferable to other research or institutional contexts. We recommend that future research use a larger sample size of international graduate students from different programs, diverse linguistic and cultural backgrounds, and transnational institutional contexts to improve the reliability and transferability of findings and analysis. For future studies, recruiting international graduate students at the doctoral level and more participants with little or no CBL experiences could help address questions surrounding the importance and viability of CBL programs in graduate education. A longitudinal research design in future studies could strengthen the findings related to the impact of CBL on international students' career and professional development.

Second, the survey and interview questions specifically developed and designed for this study may not warrant a thorough data collection on the topic. Prior studies related to international students' experiences in CBL are limited, and there was no preexisting tool to measure international graduate students' CBL experiences and perspectives. The research protocol developed for this study reflects authors' interdisciplinary backgrounds in several areas-CBL, international education, civic engagement, public policy, and higher education-therefore, some critical issues and aspects related to CBL theories and praxis might not be fully reflected in the measurement developed in this study. We recommend future research test the research protocols and examine international students' experiences in other disciplines that involve communication, human engagement, and CBL to improve the comprehensiveness and accuracy of the protocol.

Third, the findings and discussion in this article are limited by the scope of the study as well as the length of this article. As the data was collected from participants with prior CBL experiences, inherent risk lies in participants' bias toward CBL in graduate education. We did not collect data from CBL community partners. The lack of voices and perspectives of students who did not participate in CBL and CBL partner organizations can result in an incomplete depiction of the challenges and barriers in offering CBL programs to international graduate students. We recommend future studies adopt a random selection of international graduate students as participants and include perspectives of community partners to strengthen the validity and transferability of findings and implications. 


\section{Conclusion}

As half of the graduate student population in a North American higher education context are international students, exploring high-impact and inclusive graduate programs and praxis that meet international graduate students' needs is critical for the quality and sustainability of graduate education. Drawing on international graduate students' CBL experiences, this article shed light on the benefits students gained in five key areas: academic knowledge, sociocultural understanding, personal attributes, professional development, and global civic engagement. Findings of the study also revealed unique barriers that international students encounter while participating in CBL, thus calling for culturally responsive CBL program, curricula, instruction, and partnerships.

By sharing and interpreting international graduate students' voices and perspectives on CBL, the authors of this article hope to inspire scholarly conversations, collaboration, and critical inquiries that allow international graduate students to engage in global justice issues, examine the ethical responsibilities of international education, and foster skills in responsible global citizenship and civic engagement. Such conversations and inquiries are essential for innovation, sustainability, and greater inclusion in experiential education and higher education. Because non-credited community engagement and services can offer rich opportunities for global learning outcomes-an important consideration in offering CBL to international students-robust scholarly conversations on how to appropriately recognize the community engagement and services as credit-bearing global learning experiences are desirable and critical for reconceptualizing CBL in a globally interconnected higher education context.

\section{References}

Altbach, P. G., \& Knight, J. (2007). The internationalization of higher education: Motivations and realities. Journal of Studies in International Education, 11(4), 290-305. https://doi.org/10.1177/1028315307303542 Andrade, M. S. (2006). International student persistence: Integration or cultural integrity? Journal of College Student Retention: Research, Theory $\Xi^{\circ}$ Practice, 8(1), 57-81. https://doi.org/10.2190/9MY5-256H-VFVA8R8P

Ash, S. L., \& Clayton, P. H. (2009). Generating, deepening, and documenting learning: The power of critical reflection in applied learning. Journal of Applied Learning in Higher Education, 1(1), 25-48.

Baba, Y., \& Hosoda, M. (2014). Home away home: Better understanding of the role of social support in predicting cross-cultural adjustment among international students. College Student Journal, 48(1), 1-15.

Bailey, S. (2010). Academic writing for international students of business. Routledge.

Banks, J. A., \& Banks, C. A. M. (2019). Multicultural education: Issues and perspectives (10th ed.). Wiley.

Beckman, M., Brandenberger, J. W., \& Shappell, A. S. (2009). Graduate students and community-based learning. Academic Exchange Quarterly, 13(3), 45-50.

Boler, M. (1999). Feeling power: Emotions and education. Routledge.

Bowman, N. A. (2011). Promoting participation in a diverse democracy: A meta-analysis of college diver- 
sity experiences and civic engagement. Review of Educational Research, 81(1), 29-68. https://doi. org/10.3102/0034654310383047

Brauss, M. R., Lin, X., \& Baker, B. A. (2015). International students in higher education: Education and social experiences. Institute for Learning Styles Journal, 1, 54-71.

Bringle, R. G., \& Clayton, P. H. (2012). Civic education through service learning: What, how, and why? In L. McIlrath, A. Lyons, \& R. Munck(Eds.), Higher education and civic engagement: Comparative perspectives (pp. 101-124). Palgrave Macmillan.

Burnett, K. (2015, July 17). Why are international students so important to our universities? Times Higher Education. https://www.timeshighereducation.com/blog/why-are-international-students-so-important-our-universities

Canadian Bureau for International Education (CBIE). (2018). The student's voice: National results of the 2018 CBIE international student survey. https://cbie.ca/wp-content/uploads/2018/08/Student_Voice_ReportENG.pdf

Celio, C. I., Durlak, J., \& Dymnicki, A. (2011). A meta-analysis of the impact of service-learning on students. Journal of Experiential Education, 34(2), 164-181. https://doi.org/10.1177/105382591103400205

Chellaraj, G., Maskus, K. E., \& Mattoo, A. (2008). The contribution of international graduate students to US innovation. Review of International Economics, 16(3), 444-462. https://doi.org/10.1111/j.14679396.2007.00714.x

Clayton, P. H., Bringle, R. G., \& Hatcher, J. A. (Eds.). (2013). Research on service learning: Conceptual frameworks and assessment: Vol. 2a. Students and faculty. Stylus Publishing.

Coleman, J. S. (1988). Social capital in the creation of human capital. American Journal of Sociology, $94(5), 95$ -121. https://doi.org/10.1086/228943

Cowley, P., \& Hyams-Ssekasi, D. (2018). Motivation, induction, and challenge: Examining the initial phase of international students' educational sojourn. Journal of International Students, 8(1), 109-130. https://doi. org/10.5281/zenodo.1101039

Creswell, J. W. (2014). Research design: Qualitative, quantitative, and mixed methods approaches (4th ed.). Sage.

Deller, F., Brumwell, S., \& MacFarlane, A. (2015). The language of learning outcomes: Definitions and assessments. Higher Education Quality Council of Ontario.

Dostilio, L. D. (2014). Democratically engaged community-university partnerships: Reciprocal determinants of democratically oriented roles and processes. Journal of Higher Education Outreach and Engagement, 18(4), 235-244.

Duncan, J., \& Taylor, T. B. (2012). Coming full circle: A guide to service-learning. Cognella Academic Publishing.

Dunn, W., \& Olivier, C. (2011). Creating welcoming and inclusive university communities. Canadian Diversity, 8(5), 35-40.

Eyler, J. (2009). The power of experiential education. Liberal Education, 95(4), 24-31.

Foster, K. M. (2010). Taking a stand: Community-engaged scholarship on the tenure track. Journal of Community Engagement and Scholarship, 3(2), Article 3. 
Goodhue, E. K. (2017). A values-engaged approach to cultivating civic professionalism in graduate education. Michigan Journal of Community Service Learning, 24(1), 72-92.

Gresham, R., \& Clayton, V. (2011). Community connections: A program to enhance domestic and international students' educational experience. Journal of Higher Education Policy and Management, 33(4), 363-374. https://doi.org/10.1080/1360080X.2011.585736

Guo, L. (2012). Globalization: A shifting context for the Canadian education landscape. Canadian Journal of Education, 35(3), 1-3.

Guo, L., \& O’Sullivan, M. (2012). From Laoshi to partners in learning: Pedagogic conversations across cultures in an international classroom. Canadian Journal of Education, 35(3), 164-179.

Guo-Brennan, L., \& Guo-Brennan, M. (2019). Building welcoming and inclusive schools for immigrant and refugee students: Framework and promising praxis. In K. Arar, J. S. Brooks, \& I. Bogotch (Eds.), Education, immigration and migration: Policy, leadership and praxis for a changing world (pp. 73-93). Emerald Publishing.

Guo-Brennan, M., \& Guo-Brennan, L. (2019). Civic capacity and engagement in building welcoming and inclusive communities for newcomers: Praxis, recommendations, and policy implications. Journal of Community Engagement and Scholarship, 11(2), 31-42.

Hanassab, S., \& Tidwell, R. (2002). International students in higher education: Identification of needs and implications for policy and practice. Journal of Studies in International Education, 6(4), 305-322. https://doi. org/10.1177/102831502237638

Harrison, H., Birks, M., Franklin, R., \& Mills, J. (2017). Case study research: Foundations and methodological orientations. Forum: Qualitative Social Research, 18(1), Article 19. http://www.qualitative-research.net/ index.php/fqs/article/view/2655/4079.

Hatcher, J. A., \& Bringle, R. G. (Eds.). (2012). Understanding service-learning and community engagement: Crossing boundaries through research. Information Age Publishing.

Hayden, M., Levy, J., \& Thompson, J. (Eds.). (2015). The SAGE handbook of research in international education (2nd ed.). Sage.

Hegarty, N. (2014). Where we are now-The presence and importance of international students to universities in the United States. Journal of International Studies, 4(3), 223-235.

Institute of International Education (IIE). (2018, March). A world on the move: Trends in global student mobility. https://www.iie.org/Research-and-Insights/Publications/A-World-on-the-Move

Jacoby, B. (2015). Service-learning essentials: Questions, answers, and lessons learned. Jossey-Bass.

Jameson, J. K., Clayton, P. H., \& Ash, S. L. (2013). Conceptualizing, assessing, and investigating academic learning in service learning. In P. H. Clayton, R. G. Bringle, \& J. A. Hatcher (Eds.), Research on service learning: Conceptual frameworks and assessment: Vol. 2a. Students and faculty (pp. 85-110). Stylus Publishing.

Jin, X. (2006). On international trade in educational services: An interpretation of the regulations and China's WTO commitments. Frontiers of Education in China, 1(4), 601-613. https://doi.org/10.1007/s11516-0060033-0 
Kagitcibasi, C. (2007). Family, self, and buman development across cultures: Theory and applications (2nd ed.). Lawrence Erlbaum Associates.

Kim, A. H., \& Kwak, M. (2019). Outward and upward mobilities: International students in Canada, their families, and structuring institutions. University of Toronto Press.

Knutson, S. (2011). Post-secondary programs, policies and partnerships: The Case of international students at Memorial University of Newfoundland. Canadian Diversity, 8(5), 43-46.

Laird, T. F. N. (2005). College students' experiences with diversity and their effects on academic self-confidence, social agency, and disposition toward critical thinking. Research in Higher Education, 46, 365-387.

Lee, J. J., \& Rice, C. (2007). Welcome to America? International student perceptions of discrimination. Higher Education, 53(3), 381-409.

Li, X., \& Tierney, P. (2013). Internationalization in Canadian higher education: Experiences of international students in a master's program. Canadian and International Education, 42(2). http://ir.lib.uwo.ca/cgi/viewcontent.cgi ?article $=1276 \&$ context $=$ cie-eci

Lieber, E., Chin, D., Nihira, K., \& Mink, I. T. (2001). Holding on and letting go: Identity and acculturation among Chinese immigrants. Cultural Diversity and Ethnic Minority Psychology, 7(3), 247-261. https://doi. org/10.1037/1099-9809.7.3.247

Lillyman, S., \& Bennett, C. (2014). Providing a positive learning experience for international students studying at UK universities: A literature review. Journal of Research in international Education, 13(1), 63-75. https:// doi.org/10.1177/1475240914529859

Lockeman, K. S., \& Pelco, L. E. (2013). The relationship between service-learning and degree completion. Michigan Journal of Community Service Learning, 20(1), 18-30.

Mallinckrodt, B., \& Leong, F. T. L. (1992). International graduate students, stress, and social support. Journal of College Student Development, 33(1), 71-78.

Matthews, P. H., Dorfman, J. H., \& Wu, X. (2015). The impacts of undergraduate service-learning on postgraduation employment outcomes. International Journal of Research on Service-Learning and Community Engagement, 3(1). https://journals.sfu.ca/iarslce/index.php/journal/article/view/109

McNally, A. (2018). Enhancing civic, electoral, and political engagement through international student inclusion. eJournal of Public Affairs, 7(1), 25-55. http://www.ejournalofpublicaffairs.org/enhancing-engagement-through-inclusion

Medved, D., Franco, A., Gao, X., \& Yang, F. (2013). Challenges in teaching international students: Group separation, language barriers and culture differences. Lund, SE: Lund University. http://portal.research.lu.se/ws/ files/5561296/4216001.pdf

Mezirow, J. (1997). Transformative learning: Theory to practice. New Directions for Adult and Continuing Education, 74, 5-12. https://doi.org/10.1002/ace.7401

Mitchell, T. D., Donahue, D. M., \& Young-Law, C. (2012). Service learning as a pedagogy of whiteness. Equity $\Xi^{2}$ Excellence in Education, 45(4), 612-629. https://doi.org/10.1080/10665684.2012.715534 
Moore, T. L., \& Ward, K. (2010). Institutionalizing faculty engagement through research, teaching, and service at research universities. Michigan Journal of Community Service Learning, 17(1), 44-58.

Mori, S. C. (2000). Addressing the mental health concerns of international students. Journal of Counseling and Development, 78(2), 137-144. https://doi.org/10.1002/j.1556-6676.2000.tb02571.x

Myers-Walls, J. A., Frias, L. V., Kwon, K.-A., Ko, M.-J. M., \& Lu, T. (2011). Living life in two worlds: Acculturative stress among Asian international graduate student parents and spouses. Journal of comparative family studies, 42(4), 455-478.

Nita, S., Pécoud, A., De Lombaerde, P., de Guchteneire, P., Neyts, K., \& Gartland, J. (2017). Migration, free movement and regional integration. UNESCO.

Novak, J. M., Markey, V., \& Allen, M. (2007). Evaluating cognitive outcomes of service learning in higher education: A meta-analysis. Communication Research Reports, 24(2), 149-157. https://doi. org/10.1080/08824090701304881

OECD. (2019). PISA 2018 assessment and analytical framework. OECD Publishing. https://doi.org/10.1787/ b25efab8-en

Okahana, H., \& Zhou, E. (2019). International graduate applications and enrollment: Fall 2018. Council of Graduate schools. https://www.cgsnet.org/ckfinder/userfiles/files/Intl_Survey_Report_Fall2018.pdf

O’Sullivan, M. W., \& Guo, L. (2010). Critical thinking and Chinese international students: An East-West dialogue. Journal of Contemporary Issues in Education, 5(2), 53-73.

Paige, R. M., Stallman, E. M., Jon, J.-E., \& LaBrack, B. (2009, May 29). Study abroad for global engagement: The long-term impact of international experiences (Presentation). NAFSA Annual Conference, Los Angeles, California, United States. https://wiki.wooster.edu/download/attachments/45711608/Study+Abroad+for+Global+Engagement+-+The+Long-term+Impact+of+International+Experiences.pdf

Paul, R., \& Elder, L. (2014). Critical thinking: Tools for taking charge of your professional and personal life (2nd ed.). Prentice Hall.

Portes, A. (2000). Social capital: Its origins and applications in modern sociology. In E. L. Lesser (Ed.), Knowledge and social capital: Foundations and applications (pp. 43-67). Butterworth-Heinemann.

Poteet, M., \& Gomez, B. (2015). “It's both ways”: How international students negotiate belonging in local and global contexts. Journal of New Brunswick Studies, 6(1). https://journals.lib.unb.ca/index.php/JNBS/article/ view/23061

Proctor, D., \& Rumbley, L. E. (Eds.). (2018). The future agenda for internationalization in higher education: Next generation insights into research, policy, and practice. Routledge.

Reed, S. C., Rosenberg, H., Statham, A., \& Rosing, H. (2015). The effect of community service learning on undergraduate persistence in three institutional contexts. Michigan Journal of Community Service Learning, 21(2), 22-36.

Sandhu, D. S. (1994). An examination of the psychological needs of the international students: Implications for counselling and psychotherapy. International Journal for the Advancement of Counselling, 17, 229-239. 
Sharma, S. (2019). Focusing on graduate international students. Journal of International Students, 9(3), i-xi.

Sharpe, E. K., \& Dear, S. (2013). Points of discomfort: Reflections on power and partnerships in international service-learning. Michigan Journal of Community Service Learning, 19(2), 49-57.

Shek, D. \& Hollister, R. (Eds.) (2017). University social responsibility and quality of life. Springer Nature Singapore Pte Ltd.

Stake, R. E. (1995). The art of case study research. Sage.

Steinberg, K. S., Hatcher, J. A., \& Bringle, R. G. (2011). Civic-minded graduate: A north star. Michigan Journal of Community Service Learning, 18(1), 19-33.

Thompson, C. J., \& Davis, S. B. (2013). Community-based learning experiences of graduate education students within Applied Statistics and Science: Emerging insights. Journal of Community Engagement and Higher Education, 5(1), 48-56.

Thomson, G., Rosenthal, D., \& Russell, J. (2006). Cultural stress among international students at an Australian University (Paper presentation). Australian International Education Conference, Perth, Australia. https:// pdfs.semanticscholar.org/562f/de26340ea3f5c5d468c0fc7e03378e95be1f.pdf

Tran, L., \& Gribble, C. (2015, October 23). Foreign students have a valuable contribution to make. University World News. http://www.universityworldnews.com/article.php?story=20151020202131169

VanLeeuwen, C. A., Weeks, L. E., \& Guo-Brennan, L. (2017). Indigenous perspectives on community servicelearning in higher education: An examination of the Kenyan context. International Journal of Research on Service-Learning and Community Engagement, 5(1), 129-143.

VanLeeuwen, C. A., Weeks, L. E., \& Guo-Brennan, L. (2019). Critical pedagogy of discomfort in communitybased learning: Kenyan students' experiences. Comparative and International Education, 48(1), Article 4. https://doi.org/10.5206/cie-eci.v48i1.9336

Vavrus, F., \& Pekol, A. (2015). Critical internationalization: Moving from theory to practice. FIRE: Forum for International Research in Education, 2(2). http://dx.doi.org/10.18275/fire201502021036

Vygotsky, L. S. (1978). Mind in society: The development of higher psychological processes. Harvard University Press.

Wagner, T. (2008). The global achievement gap: Why even our best schools don't teach the new survival skills our children need - and what we can do about it. Basic Books.

Warren, J. L. (2012). Does service-learning increase student learning? A meta-analysis. Michigan Journal of Community Service Learning, 18(2), 56-61.

Whitney, B. C., \& Clayton, P. H. (2011). Research on and through reflection in international service learning. In R. G. Bringle, J. A. Hatcher, \& S. G. Jones (Eds.), International service learning: Conceptual frameworks and research (pp. 145-188). Stylus Publishing.

Yeh, C. J., \& Inose, M. (2003). International students' reported English fluency, social support satisfaction, and social connectedness as predictors of acculturative stress. Counselling Psychology Quarterly, 16(1), 15-28. https://doi.org/10.1080/0951507031000114058

Yellig, A. (2011). The experiences of married international graduate students and their accompanying non-student 
spouses in the US culture: A qualitative study (Doctoral dissertation, Western Michigan University). Dissertations 485. https://scholarworks.wmich.edu/dissertations/485

Ying, Y., \& Liese, L. H. (1991). Emotional well-being of Taiwan students in the U.S.: An examination of preto post-arrival differential. International Journal of Intercultural Relations, 15(3), 345-366. https://doi. org/10.1016/0147-1767(91)90007-4

Yorio, P. L., \& Ye, F. (2012). A meta-analysis on the effects of service-learning on the social, personal, and cognitive outcomes of learning. Academy of Management, 11(1), 9-27. https://doi.org/10.5465/amle.2010.0072

Yuan, F., \& Izuma, K. (2018). Social capital and Chinese international students' use of social network site in the UK. International Journal of School and Cognitive Psychology, 5(2). https://doi.org/10.4172/24699837.1000209

Zembylas, M., \& McGlynn, C. (2012). Discomforting pedagogies: Emotional tensions, ethical dilemmas and transformative possibilities. British Educational Research Journal, 38(1), 41-59. https://doi.org/10.1080/01 411926.2010 .523779

\section{Authors}

LINYUAN GUO-BRENNAN is Associate Professor of International and Global Education in the Faculty of Education, University of Prince Edward Island, Canada. Her teaching and research interests include international and comparative education, global citizenship, global leadership, higher education, teacher education, community engagement, and immigration.

CHARLENE VANLEEUWEN is a postdoctoral researcher at Royal Roads University and an instructor at the University of Prince Edward Island, Canada. Her areas of research interest include international communitybased learning and innovations in digital education using primarily qualitative methods.

MARY M. MACPHEE is Adjunct Faculty in the Faculty of Education, University of Prince Edward Island, Canada. Her teaching and research interests include French teacher preparation, parental involvement in education, French minority-language education, French immersion, and community engagement.

MICHAEL GUO-BRENNAN is Assistant Professor in the Department of Political Science, Troy University, United States. His teaching and research focus on public policy and affairs, governmental relations, public administration, leadership development, and civic engagement. 


\section{Appendix A}

\section{Community-Based Learning (CBL) Survey for International Graduate Students}

\section{Questions on Demographic Background}

1. I am/was an international graduate student who participated in community-based learning through UPEI M.Ed. graduate program or courses. Yes No

If your answer is No, please go to the end of the survey and answer the last question.

If your answer is YES, please continue to complete the following questions and survey:

2. I come from (country).

3. Other than English, I can communicate (write/read/speak) in (please list all languages).

4. I am/was an international graduate student in (the name of your program).

5. I have participated in community-based learning in the following ways: (Select all that apply to you.)

a. ED 601 - Work-place learning course

b. Community-based learning activities built into other courses

c. Service learning and community engagement opportunities in the graduate program (e.g., courses on leadership, curriculum, seminar, etc.)

d. Volunteer activities with local community organizations

e. Other (please specify)

f. I have participated in community-based learning in the following organizations (please choose all that apply):

g. Public education sector (K-12 schools)

6. Higher education sector (colleges, universities, adult training organizations)
a. Nonprofit organizations (charity, community services, etc.)
b. Government
c. Health sector
d. Private sector (business, tutoring, etc.)
e. Other (please provide some details) 


\section{Statements on the Impact of Community-Based Learning}

Please indicate your level of agreement with the following statements related to the impact of CBL on academic, sociocultural, personal, professional, and global citizenship development. Please use one of the following six options to express your feeling/opinion: Strongly Disagree, Disagree, Not Sure, Agree, Strongly Agree, Not Applicable.

\begin{tabular}{|c|c|c|c|c|c|c|}
\hline CBL Statements & $\begin{array}{l}\text { Strongly } \\
\text { Disagree }\end{array}$ & Disagree & Not Sure & Agree & $\begin{array}{l}\text { Strongly } \\
\text { Agree }\end{array}$ & $\begin{array}{c}\text { Not } \\
\text { Applicable }\end{array}$ \\
\hline \multicolumn{7}{|c|}{ Academic } \\
\hline $\begin{array}{l}\text { 1. The community service aspect of graduate program/ } \\
\text { courses helped me to see how the subject matter } \\
\text { I learned can be applied in real workplaces and } \\
\text { everyday life. }\end{array}$ & $\square$ & $\square$ & $\square$ & $\square$ & $\square$ & $\square$ \\
\hline $\begin{array}{l}\text { 2. Community-based learning had a positive impact } \\
\text { on my academic work and learning. }\end{array}$ & $\square$ & $\square$ & $\square$ & $\square$ & $\square$ & $\square$ \\
\hline $\begin{array}{l}\text { 3. Community-based learning helped me to connect } \\
\text { the graduate curriculum/course content with practi- } \\
\text { cal knowledge and skills. }\end{array}$ & $\square$ & $\square$ & $\square$ & $\square$ & $\square$ & $\square$ \\
\hline $\begin{array}{l}\text { 4. Community-based learning provides more oppor- } \\
\text { tunities to improve English communication skills } \\
\text { outside of classroom settings. }\end{array}$ & $\square$ & $\square$ & $\square$ & $\square$ & $\square$ & $\square$ \\
\hline $\begin{array}{l}\text { 5. Community-based learning provides more opportu- } \\
\text { nities for me to enhance skills in creative and critical } \\
\text { thinking. }\end{array}$ & $\square$ & $\square$ & $\square$ & $\square$ & $\square$ & $\square$ \\
\hline $\begin{array}{l}\text { 6. My interactions with the community partner en- } \\
\text { hanced my learning in graduate program/courses. }\end{array}$ & $\square$ & $\square$ & $\square$ & $\square$ & $\square$ & $\square$ \\
\hline
\end{tabular}

Sociocultural

7. Community-based learning provides opportunities for me to encounter perspectives, values, beliefs, and workplaces different from the ones I am familiar with.

8. Community-based learning provides increased opportunities for cross-cultural understanding and communication.

9. Community-based learning provides more opportunities for building meaningful social and professional relationships.

10. The service I performed in the community enhanced my ability to communicate in a "real world" setting

Personal Development

11. The community service involved in graduate program/courses made me more aware of my own perspectives and biases.

12. The community service aspect of graduate program/ courses helped me to develop my problem-solving skills. 
13. Community service-learning helped me become more comfortable working with people different from myself.

14. Participating in the community helped me enhance my leadership skills.

\section{Professional Development}

15. Performing service in the community helped me identify new career opportunities.

16. The community service in graduate program/courses helped me clarify my career/life plans.

17. The community service in graduate program/courses is beneficial in applying for a post-graduate work permit or immigration to Canada.

18. I would have learned more from graduate program/ courses if more time was spent in the classroom instead of in the community.

\section{Civic Engagement and Global Citizenship}

19. I was already volunteering in the host community before taking any service-learning course.

20. Most people can make a difference in their community.

21. As an international student, I have a responsibility to serve the host organization and community.

22. The community service involved in graduate program/courses helped me to become more aware of the needs in the host community and my home country.

23. The community service I did through graduate program/courses benefited the host community.

24. CBL enhanced my understanding of and commitment to global justice issues.

25. Through CBL, I became more committed to addressing community or social problems as a global citizen.

26. I became more confident in taking actions which make a difference in local and global communities.

27. CBL helped me understand and appreciate volunteerism and civic participation in society.

28. My international perspective/experience is an added value to host communities and organizations.

29. CBL helped me to become a more active and responsible community member and global citizen.

\section{Overall}

30. The idea of combining service in the community with graduate coursework should be practiced in more graduate classes.

31. I probably won't volunteer or participate in the community after graduate program/courses.

32. My international student status presents challenges and difficulties for community-based learning (visa, etc.)

33. International students will benefit more if all graduate programs offer community service-learning opportunities. 


\section{Appendix B}

\section{Interview Protocol}

1. In what ways has community-based learning or CBL contributed to your academic performance in graduate studies? (For example, some students say that CBL has helped them with curriculum, language, content, relationships, etc.)

2. In what ways has CBL contributed to your sociocultural relationships and cross-cultural understanding and skills?

3. In what ways has CBL influenced your personal development?

4. In what ways has CBL influenced your professionalism and career planning?

5. What opportunities does CBL provide that you cannot get from in-classroom experiences as a graduate student?

6. What benefits and advantages have you gained from CBL?

7. What barriers and challenges have you experienced during CBL?

8. What can be changed to make CBL more beneficial for students/you?

9. What can be changed to improve CBL experiences for the host community organizations?

10. What other thoughts would you like to share about the impact of CBL for international graduate students? 